\title{
Формирование $p$-эмиттера с участием сурфактантов в GaAs фотоэлектрических преобразователях
}

\author{
(С) Л.Б. Карлина, А.С. Власов, Б.Я. Бер, Д.Ю. Казанцев, Н.Х. Тимошина, \\ М.М. Кулагина, А.Б. Смирнов
}

Физико-технический институт им. А.Ф. Иоффре Российской академии наук, 194021 Санкт-Петербург, Россия

E-mail: karlin@mail.ioffe.ru

(Получена 12 декабря 2016 г. Принята к печати 19 декабря 2016 г.)

\begin{abstract}
Приведены сравнительные характеристики фотовольтаических преобразователей лазерного излучения на основе арсенида галлия с $p$-эмиттером, сформированным диффузией из газовой фазы в присутствии сурфактантов (изовалентных примесей) и без них. Показано, что использование индия и фосфора в процессе формирования $p-n$-перехода существенно влияет на характеристики полученных приборов.
\end{abstract}

DOI: 10.21883/FTP.2017.05.44432.8477

\section{1. Введение}

Диффузия цинка в материалы $\mathrm{A}^{\mathrm{III}} \mathrm{B}^{\mathrm{V}}$ с целью формирования $p-n$-переходов продолжает активно использоваться при изготовлении фотоэлектрических преобразователей солнечного и лазерного излучений [1-3]. Способы оптимизации процесса диффузии рассматриваются с точки зрения разных источников цинка (например, $\mathrm{Ga}-\mathrm{Zn}$ ) [4], роли окислов на поверхности перед процессом диффузии [5], а также состояния поверхности, в частности ее микрорельефа, который, по мнению авторов, может улучшать параметры приборов на основе этих структур [6].

Метод диффузии, предложенный нами ранее [7], значительно упрощает процесс диффузии цинка, и последующее изготовление приборов на основе соединений $\mathrm{A}^{\mathrm{III}} \mathrm{B}^{\mathrm{V}}$ с $p$-эмиттером. Он позволяет исключить двухстадийный процесс диффузии, снизить рекомбинацию на поверхности и в объеме $p$-слоя при его высоком уровне легирования, исключить дополнительные операции по травлению верхнего „мертвого“ слоя.

Требования к $p$-эмиттеру в структурах для фотоэлектрических преобразователей должны отвечать нескольким условиям. Прежде всего это оптимальная толщина $p$-области, т.е. глубина $p-n$-перехода, обеспечивающая как достаточную спектральную чувствительность, так и необходимое сопротивление растекания, которое влияет на величину омических потерь. Снижение рекомбинации при высоком уровне легирования $p$-слоя позволяет получить низкоомный контакт на фронтальной поверхности элемента.

Данное исследование является продолжением работ по модификации (в т.ч. пассивации) поверхности арсенида галлия с использованием изовалентных примесей [7-9]. В настоящей работе приведены сравнительные характеристики фотоэлектрических преобразователей и анализ влияния сурфактантов на формирование p-эмиттера, полученного диффузией цинка в присутствии индия и фосфора.

\section{2. Эксперимент}

Для формирования $p-n$-перехода использовался метод диффузии цинка из газовой фазы в потоке водорода, при котором источником цинка служил раствор-расплав $\mathrm{Zn}-\mathrm{Sn}$. Диффузия осуществлялась в предварительно модифицированные подложки арсенида галлия, которые содержали некоторое количество сурфактантов (индия и фосфора) на поверхности и в приповерхностном слое. Подробно этот процесс был описан нами ранее [7]. В качестве подложек использовались пластины „еріready“ GaAs $n$-типа, отклоненные на $6^{\circ}$ в направлении $[111]_{\mathrm{A}}$, легированные кремнием, а также подложки $\mathrm{GaAs}$ после химико-механической обработки. Уровень легирования подложек составлял от $n(2-4) \cdot 10^{16}$ до $(1-3) \cdot 10^{18} \mathrm{~cm}^{-3}$. В качестве контрольных образцов использовались подложки, вырезанные из того же материала, но без предварительной диффузии сурфактантов.

Контроль состояния поверхности арсенида галлия до и после диффузии цинка изучался с помощью атомносилового микроскопа Интегра-Аура. Исследования велись как в контактном режиме, так и в режиме прерывистого контакта в атмосферных условиях при комнатной температуре.

Профиль распределения цинка, индия и фосфора в $\mathrm{GaAs}$ определялся методом динамической вторичноионной масс-спектрометрии (ВИМС) [7].

Концентрация свободных носителей контролировалась методом комбинационного рассеяния света. Фронтальный контакт к р-области изготавливался с использованием фотолитографии и напыления композиции $\mathrm{Cr} / \mathrm{Au}$ без дополнительного вжигания. При этом температура образцов при напылении не превышала $60^{\circ} \mathrm{C}$. Контакт к $n$-подложке формировался последовательным напылением $\mathrm{Au} / \mathrm{Ge}-\mathrm{Ni}-\mathrm{Au}$ и дополнительным вжиганием. Утолщение контактов осуществлялось электролитическим осаждением золота. Площадь изготовленных элементов $3.5 \times 3.5$ мм. Просветляющее покрытие не наносилось. 

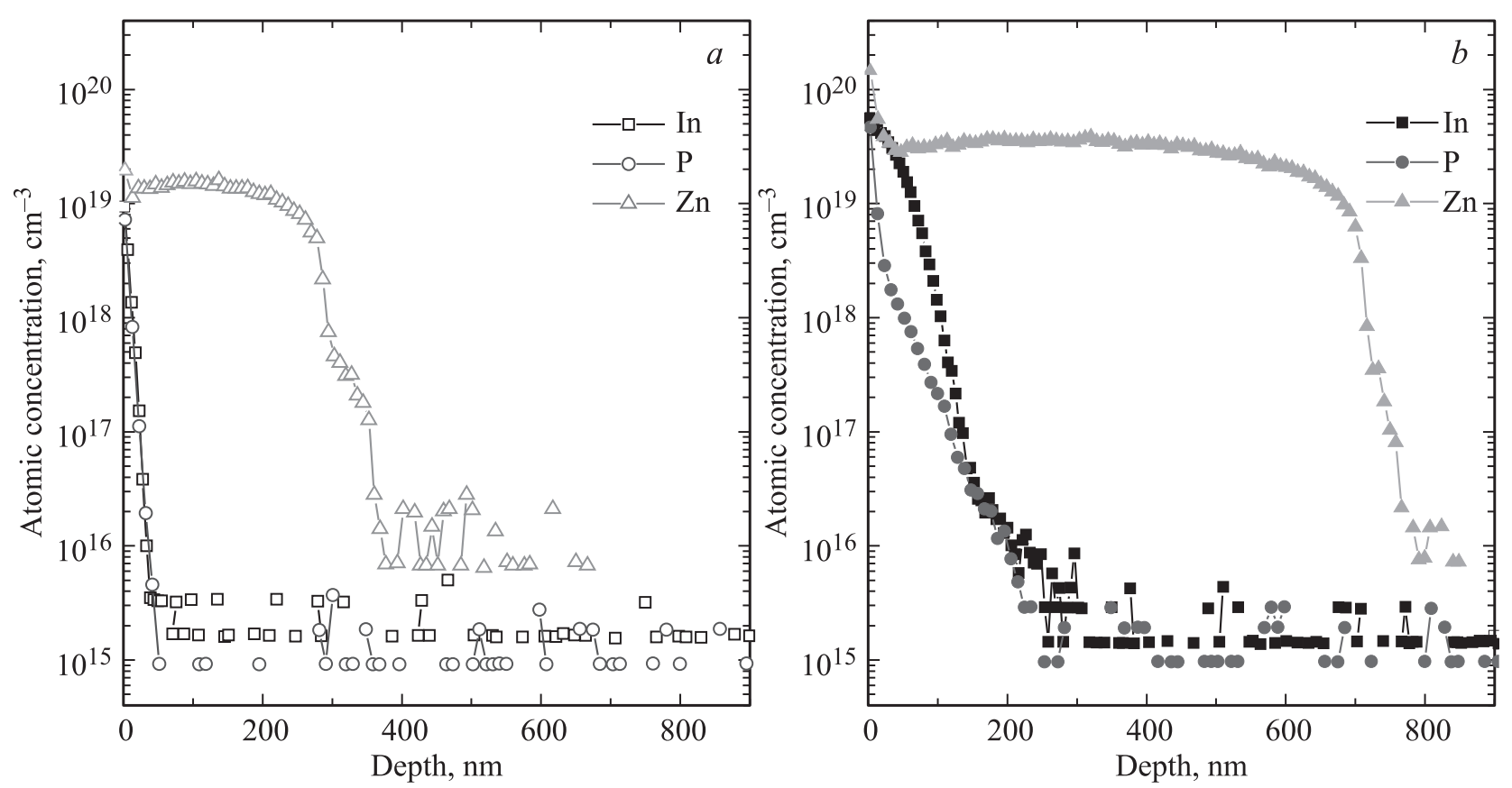

Рис. 1. ВИМС профили Zn (треугольники), In (квадраты) и $\mathrm{P}$ (кружки) после диффузии цинка в арсенид галлия $\left(n=3 \cdot 10^{16} \mathrm{~cm}^{-3}\right)$ : $a$ - без предварительной обработки, $b-$ - образец с большим содержанием сурфактантов.

При измерении параметров полученных фотопреобразователей была использована установка для исследования вольт-амперных характеристик ФП с лазерным источником непрерывного излучения $(\lambda=830$ нм, диаметр волокна 200 нм).

\section{3. Результаты и обсуждение}

Состояние поверхности во многом определяет дальнейшее развитие технологических процессов роста или диффузии примесей. Известно, что шероховатость поверхности сильно зависит от условий отжига $[10,11]$. Проведенные нами измерения показали, что модификация поверхности арсенида галлия в присутствии индия и фосфора (отжиг) уменьшала шероховатость поверхности, как epi-ready' подложек, так и механически полированных. Определенные из этих измерений значения среднеквадратичной шероховатости $R_{q}$ после отжига находились в пределах 0.19-0.76 nm. Последующая диффузия цинка не изменяла величину шероховатости.

Особенности процесса диффузии цинка в присутствии In и $\mathrm{P}$ в GaAs-подложке, легированные оловом с концентрацией носителей $(1-3) \cdot 10^{18} \mathrm{~cm}^{-3}$, были описаны нами ранее [7]. Было показано, что увеличение относительной концентрации индия в парах In, P увеличивает скорость диффузии цинка, а следовательно контролирует глубину $p-n$-перехода. В этой работе мы дополнительно рассмотрели формирование диффузионного слоя в слабо легированных подложках арсенида галлия $n \sim(1-3) \cdot 10^{16} \mathrm{~cm}^{-3}$. На рис. 1 показаны ВИМС профили цинка, индия и фосфора в образцах с различ- ным содержанием предварительно введенных сурфактантов. Диффузия цинка в оба образца осуществлялась в одном режиме (одновременно) при температуре $670^{\circ} \mathrm{C}$, время диффузии 1 ч.

Как видно из рис. 1, при одинаковых условиях процесса глубина $p-n$-перехода и концентрация цинка значительно отличаются. Рост концентрации индия в приповерхностной области GaAs приводит к значительному увеличению глубины диффузии цинка и его концентрации в объеме слоя.

Ранее было показано, что процесс изотермической диффузии может быть описан в рамках рекомбинационной модели, при которой концентрационный профиль цинка определяется концентрационным профилем вакансий галлия [12]. В нашей предыдущей работе [7] мы обнаружили, что диффузия цинка в арсенид галлия при изотермических условиях может также контролироваться соотношением сурфактантов (индия и фосфора), т. е. количество вакантных мест для встраивания атомов цинка может быть задано первоначальной модификацией поверхности. Как видно из рис. 1, содержание индия и фосфора в предполагаемой области $p$-n-перехода находится на уровне фона. Таким образом, сурфактанты, находящиеся на поверхности и в приповерхностной области арсенида галлия, определяют сам процесс диффузии, но слабо влияют на область вблизи $p-n$-перехода. Анализ этих данных и сравнение их с результатами, полученными нами ранее [7], позволили сделать вывод о том, что скорость диффузии цинка в присутствии сурфактантов зависит также от концентрации примеси в арсениде галлия. 

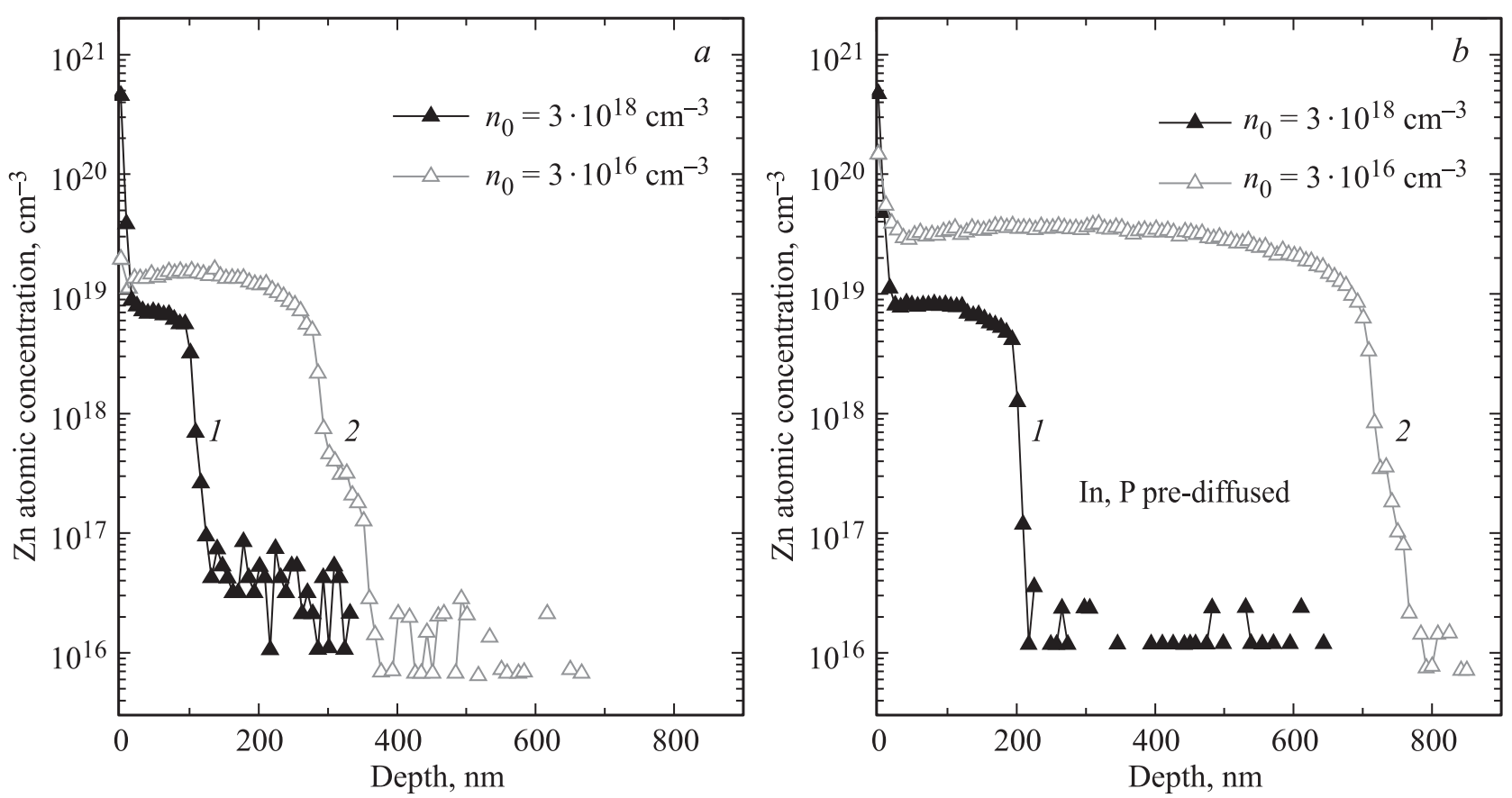

Рис. 2. ВИМС профили $\mathrm{Zn}$ после диффузии в арсенид галлия $n$-типа с различным уровнем легирования: $n_{0} \approx 3 \cdot 10^{18} \mathrm{~cm}^{-3}$ (линия 1 ) и $n_{0} \approx 3 \cdot 10^{16} \mathrm{~cm}^{-3}$ (линия 2). $a-$ подложки без предварительной обработки, $b-$ подложки с предварительной диффузией индия и фосфора.

На рис. 2 показаны профили распределения цинка, полученные в результате диффузии цинка в подложки GaAs с уровнем легирования $\sim 3 \cdot 10^{16}$ и $3 \cdot 10^{18} \mathrm{~cm}^{-3}$. Условия диффузии и предварительной обработки в паpax In, Р были одинаковые. Из рисунка видно, что скорость диффузии в равной степени определяется как начальным уровнем легирования подложки, так и присутствием индия в приповерхностном слое.

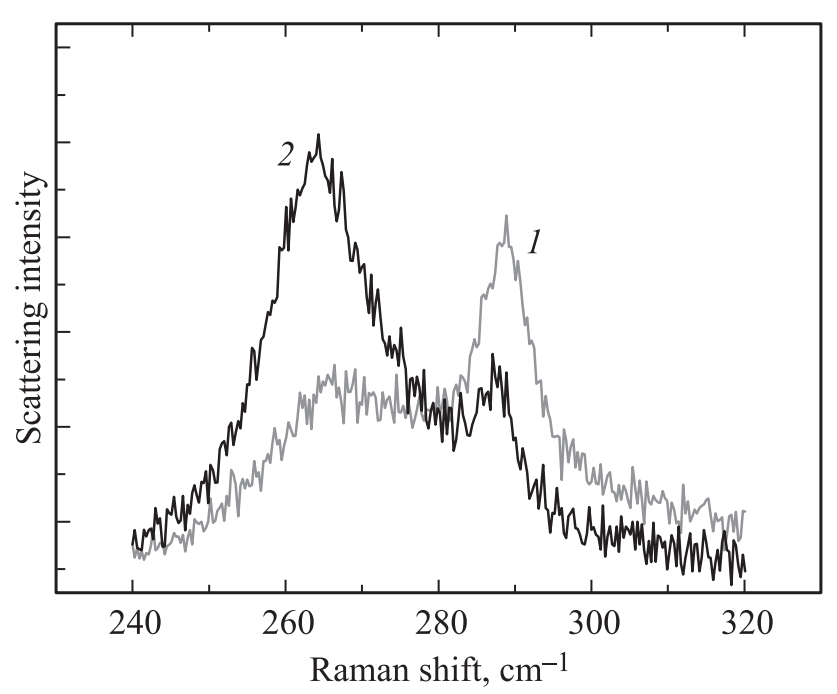

Рис. 3. Спектры рамановского рассеяния образцов GaAs после диффузии $\mathrm{Zn}$ без предварительной обработки (линия 1) и после предиффузии In, P (линия 2).
Концентрация электрически активного цинка была измерена с использованием рамановской спектроскопии (рис. 3). Глубина проникновения лазерного излучения 532 нм в GaAs составляет $\sim 100$ нм, что позволяет контролировать концентрацию примеси в объеме исследуемых слоев. На рис. 3 приведены спектры рамановского рассеяния в геометрии $z(x, y) z$ для анализируемых образцов. Спектры образцов после диффузии $\mathrm{Zn}$ без предварительной обработки и с предиффузией In, P демонстрируют концентрации свободных носителей на уровне $1 \cdot 10^{19}$ и $4 \cdot 10^{19} \mathrm{~cm}^{-3}$ соответственно. Указанные значения хорошо согласуются с данными ВИМС (рис. 1), что говорит о высокой степени ионизации атомов цинка после диффузии. Небольшое усиление интенсивности рассеяния для образца с предварительной обработкой вызвано слабовыраженным эффектом гигантского рамановского рассеяния, природа появления которого рассматривалась нами ранее [13].

\section{4. Параметры полученных приборов}

Известно, что глубина $p-n$-перехода $(d)$ определяет спектральную чувствительность и сопротивление растекания вдоль слоя. На рис. 4 показаны спектральные характеристики приборов с различными эмиттерами, которые могут быть сформированы путем соответствующего выбора предварительно введенных сурфактантов. Режим диффузии цинка для всех образцов был одинаков. 


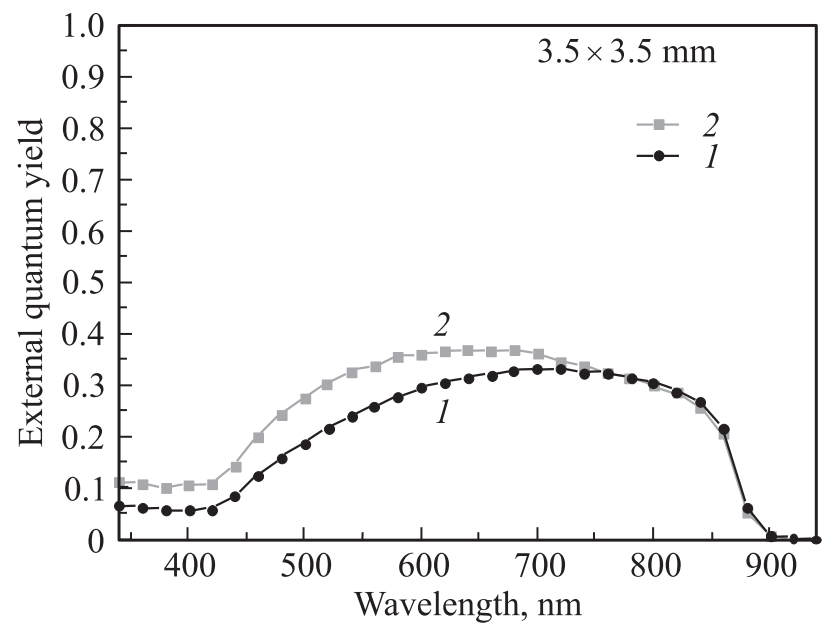

Рис. 4. Спектральные характеристики внешнего квантового выхода фотоэлектрических преобразователей на основе GaAs с различными глубинами залегания $p-n$-перехода: $1-$ контрольный образец, $d=150 \mathrm{HM}, I_{s c}-8.17 \mathrm{MA} / \mathrm{cm}^{2}$ (AM1.5D 320-940 нм); 2 - содержащий In и $\mathrm{P}, d=240$ нм, $I_{s c}-9.45 \mathrm{MA} / \mathrm{cm}^{2}$. Концентрация дырок в эмиттере образца: $1-p=1 \cdot 10^{19} \mathrm{~cm}^{-3}, 2-p=5 \cdot 10^{19} \mathrm{~cm}^{-3}$.

Для фотоэлектрических приборов, работающих в сильноточных режимах, таких как преобразование концентрированного солнечного и лазерного излучений, выбор оптимальной толщины $p$-GaAs слоя и его легирования является важным этапом оптимизации процесса изготовления прибора.

Данная работа предполагала оптимизацию приборов для преобразования лазерного излучения. Как было показано выше, концентрация электрически активной примеси увеличивается в присутствии сурфактантов. Снижение рекомбинации в объеме и на поверхности диффузионного слоя [7] приводит к увеличению диффузионной длины неосновных носителей. Меняя режимы введения сурфактантов, можно управлять глубиной залегания $p-n$-перехода и его характеристиками при неизменных условиях диффузии цинка.

Полученные результаты показывают увеличение концентрации примеси в $p$-слое, при сохранении высокой плотности тока, если сурфактанты присутствуют. Это свидетельствует о том, что происходит увеличение диффузионной длины неосновных носителей, обусловленное снижением рекомбинации, как и было показано нами ранее [7].

Для оценки влияния условий формирования эмиттера на конечные параметры преобразователей лазерного излучения были выбраны образцы с p-слоем, сформированным с сурфактантами и без них. Спектральные характеристики этих образцов представлены на рис. 4. Можно обратить внимание на то, что, несмотря на большую толщину эмиттера, у образца с предварительной обработкой наблюдается увеличение квантового выхода в коротковолновой части спектра, что свидетель- ствует об эффективной пассивации поверхности GaAs. Нагрузочные характеристики приборов содержащих In и Р, также демонстрируют улучшение характеристик во всем исследованном диапазоне плотностей тока (рис. 5, 6).

Как видно из рисунков, только за счет изменения первоначальных условий для формирования эмиттера наблюдается значительное улучшение основных параметров фотопреобразователя и повышение его кпд.

Следует еще раз отметить, что данная работа проводилась без дополнительной оптимизации самой структуры элемента (выращивания дополнительных слоев либо использования просветляющих покрытий), т. е. рассматривался только процесс оптимизации материала эмиттера путем управления процессом диффузии цинка с помощью введения сурфактантов.
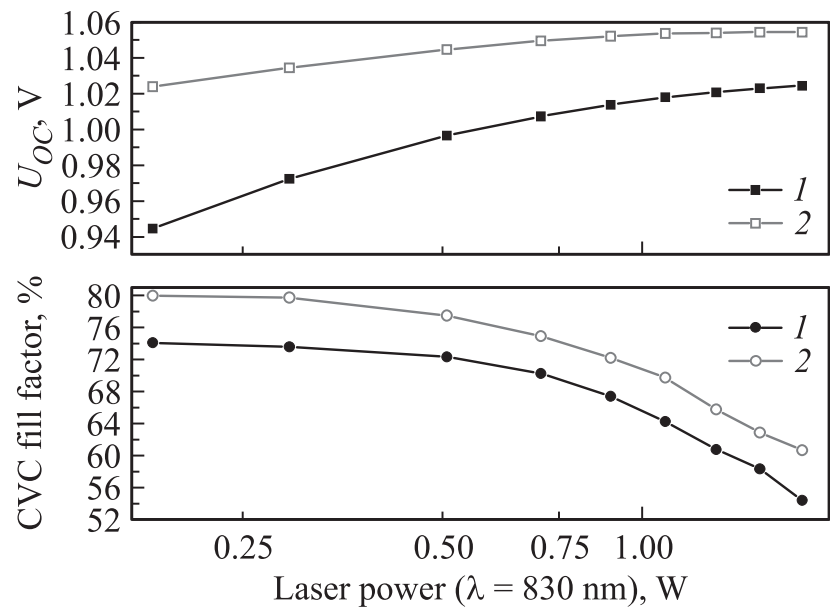

Рис. 5. Параметры лазерных фотоэлектрических преобразователей с эмиттером сформированным без сурфактантов (кривая 1) и с участием сурфактантов (кривая 2).

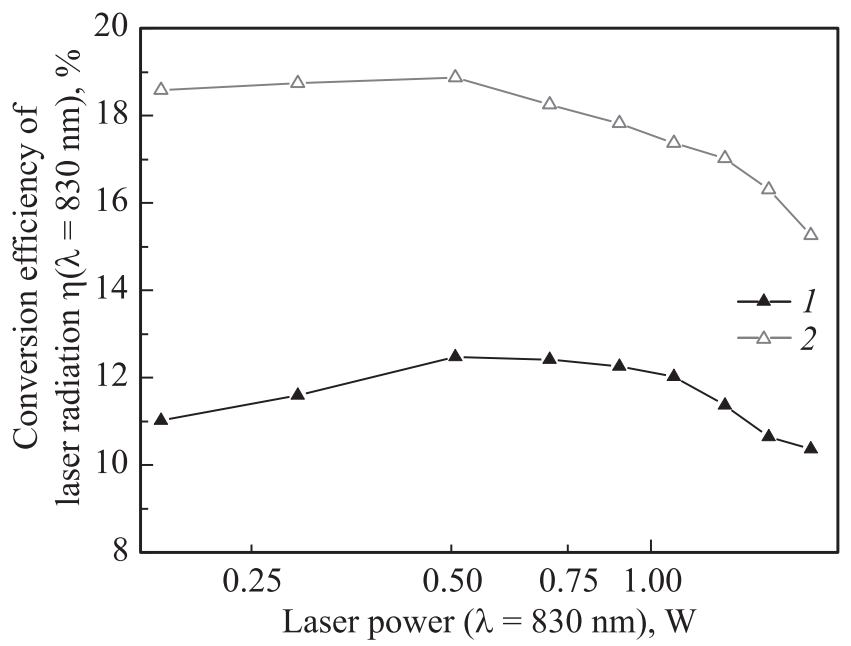

Рис. 6. Монохроматическая эффективность преобразователя в зависимости от мощности лазерного излучения для приборов с эмиттером, сформированным без сурфактантов (кривая 1) и с участием сурфактантов (кривая 2). 


\section{5. Заключение}

Метод формирования $p-n$-перехода в арсениде галлия диффузией цинка с участием сурфактантов индия и фосфора обеспечивает получение эмиттеров с малой рекомбинацией на поверхности и в объеме $p$-слоя при высоком уровне легирования $\left(p=(4-9) \cdot 10^{19} \mathrm{~cm}^{-3}\right)$.

Приведены сравнительные характеристики ФП на основе GaAs c p-эмиттером, сформированным с участием сурфактантов и без них. Установлено, что при возбуждении излучением $\lambda=830$ нм такие фотопреобразователи показывают увеличение кпд на $15-20 \%$ по сравнению с приборами, изготовленными без дополнительного введения сурфактантов.

Работа выполнена при поддержке Российского научного фонда (грант № 14-29-00178). ВИМС измерения выполнялись в ЦКП „Материаловедение и диагностика в передовых технологиях“(ФТИ им. А.Ф. Иоффе), поддерживаемом Министерством образования и науки России.

Авторы выражают благодарность А.В. Анкудинову за проведение измерений методом атомно-силовой микроскопии и С.И. Трошкову за измерения глубины залегания $p-n$-переходов методом электронной микроскопии.

\section{Список литературы}

[1] S.P. Chang. Adv. Mater. Res., 684, 312 (2013).

[2] N.L. Dmitruk, O.Yu. Borkovskaya, A.V. Korovin, I.B. Mamontova, V.R. Romanyuk, A.V. Sukach. Solar Energy Mater. \& Solar Cells, 137, 124 (2015).

[3] Liangliang Tang, Hong Ye, Jiu Xu. Solar Energy Mater. \& Solar Cells, 122, 94 (2014).

[4] Hong Ye, Qing Ni. J. Mater. Sci., 51, 15 (2016).

[5] T. Schlegl, O.V. Sulima, A.W. Bett. AIP Conf. Proc., 738, 396 (2004).

[6] А.А. Акопян, Х.Н. Бахронов, О.Ю. Борковская, Н.Л. Дмитрук, Д.М. Ёдгорова., А.В. Каримов, Р.В. Конакова, И.Б. Мамонтова. ФТП, 43, 585 (2009).

[7] L.B. Karlina, A.S. Vlasov, B.Y. Ber, D.Y. Kazantsev. J. Cryst. Growth, 432, 1338 (2015).

[8] A.S. Vlasov, L.B. Karlina, M.Z. Shvarts, N.K. Timoshina, B.Y. Ber, D.Y. Kazantsev. Proc. 29rd Eur. Photovoltaic Solar Energy Conf. (Amsterdam, the Netherlands, September, 2226, 2014) p. 2054.

[9] L.B. Karlina, A.S. Vlasov, B.Y. Ber, D.Yu. Kazanthev, E.P. Marukhina. J. Cryst. Growth, 380, 138 (2013).

[10] Hiroaki Morota, Sadao Adachia. J. Appl. Phys., 105, 043508 (2009).

[11] I.O. Akhundova, V.L. Alperovicha, A.V. Latysheva, A.S. Terekhov. Appl. Surf. Sci., 269, 2 (2013).

[12] Н.Н. Григорьев, Т.А. Кудыкина. ФТП, 31, 697 (1997).

[13] А.С. Власов, Л.Б. Карлина, Ф.Э. Комисаренко, А.В. Анкудинов. ФТП, принято в печать.

\section{Formation of $p$-emitter in GaAs photoconverters in the presence of surfactants}

\author{
L.B. Karlina, A.S. Vlasov, B.Y. Ber, D.Y. Kazantsev, \\ N.Kh. Timoshina, M.M. Kulagina, A.B. Smirnov \\ loffe Institute, \\ 194021 St. Petersburg, Russia
}

\begin{abstract}
Comparison of the spectral photoresponse of photovoltaic converters based on GaAs with $p$-emitter created by diffusion from gas phase in the presence of surfactants (isovalent impurities) and without the latter. It is shown that use of Indium and phosphorous during the emitter formation seriously implies the device characteristics.
\end{abstract}

